\title{
Effect of low frequency pulsed magnetic field on gravitropic response and cell elongation in coleoptiles of maize seedlings
}

\author{
Anna Kościarz-Grzesiok ${ }^{1}$, Karolina Sieroń-Stołtny ${ }^{1}$, Malgorzata Polak ${ }^{2}$, Aleksander Sieroń ${ }^{1}$ \\ and Waldemar Karcz ${ }^{3}$ \\ ${ }^{1}$ Chair and Clinic of Internal Diseases, Angiology and Physical Medicine, Silesian Medical University, Bytom, Poland \\ ${ }^{2}$ Department of Cell Biology, Faculty of Biology and Environmental Protection, University of Silesia, Jagiellońska 28, Katowice, \\ Poland \\ ${ }^{3}$ Department of Plant Physiology, Faculty of Biology and Environmental Protection, University of Silesia, Jagielloniska 28, \\ Katowice, Poland
}

\begin{abstract}
The effect of pulsed magnetic field (PMF) on gravitropic response, endogenous growth and growth in the presence of indole-3-acetic acid (IAA) was studied in coleoptiles of maize (Zea mays L.) seedlings. Medium $\mathrm{pH}$ changes, measured simultaneously with growth of coleoptile segments, were also determined. In seedlings grown in the presence of PMF, elongation growth of coleoptiles was inhibited by $16 \%$, while growth of roots and mesocotyls did not depend on PMF. Magnetic field also inhibited (by 36\%) the gravitropic response of maize seedlings. However, when PMF was applied only during gravistimulation (within $6 \mathrm{~h}$ ), it suppressed the gravitropic reaction only by $8 \%$ at $6 \mathrm{~h}$. It was also found that endogenous growth and IAA-induced growth of maize coleoptile segments excised from seedlings treated with the PMF was stimulated by $52 \%$ and $30 \%$, respectively, as compared to control (segments untreated with the PMF). Values of medium $\mathrm{pH}$, measured simultaneously with growth, indicated that PMF-treated coleoptile segments extruded much more protons than untreated segments. In contrast, coleoptile segments treated with the PMF and subsequently incubated in the presence of IAA extruded 2.5-fold less protons as compared to segments treated with IAA only. The data presented here have been discussed with consideration of mechanisms by which auxin (IAA) regulates plant cell growth.
\end{abstract}

Key words: Auxin - Coleoptile segments - Elongation growth - Gravitropic response - Medium $\mathrm{pH}$ - Pulsed magnetic field

\section{Introduction}

It is well established that plant growth and development are tightly regulated by plant hormones, among which indole3 -acetic acid (IAA) plays a key role, and abiotic factors, including the magnetic field (MF) (reviewed in Belyavskaya 2004; Galland and Pazur 2005; Minorsky 2007; Dhawi 2014; Maffei 2014; Occhipinti et al. 2014; Teixeira da Silva and Dobránszki 2015, 2016). Literature data included in the above mentioned papers clearly indicate that the magnetic field

Correspondence to: Waldemar Karcz, Department of Plant Physiology, Faculty of Biology and Environmental Protection, University of Silesia, Jagiellońska 28, 40-032 Katowice, Poland E-mail: waldemar.karcz@us.edu.pl may affect plant growth and development both positively and negatively. The biological effects of magnetic field depend on its properties, such as flux density or frequency, as well as on the pretreatment of biological material and duration of treatment. In spite of the large number of papers published on the effect of magnetic field on plants, little is known about the molecular mechanism of its effect on the auxin (IAA)induced elongation growth in plant cells.

The effect of auxin on plant cell elongation and proton extrusion is a well-studied aspect of auxin action. Correlation between the IAA-induced proton efflux and acceleration of elongation growth proves the so called "acid growth theory", which explains the mechanism of auxin-induced growth (for review see Hager 2003). In agreement with this theory, auxin increases either the activity or the amount of plasma mem- 
brane $\mathrm{H}^{+}$-ATPase that pumps protons into the cell wall and therefore lowers its pH (Rayle and Cleland 1970, 1992; Hager et al. 1971, 1991). In turn, lower $\mathrm{pH}$ directly decreases the yield threshold of the wall and optimizes the activity of cell wall-localized proteins that loosen the wall (for review see Hager 2003). Both processes provide favourable conditions for cell elongation. Activation of the proton pump by auxin also causes hyperpolarization of the membrane potential and activation of $\mathrm{K}^{+}$uptake channels, activity of which contributes to water uptake necessary for cell expansion (Cleland et al. 1977; Keller and Van Volkenburgh 1996; Philippar et al. 1999; Becker and Hedrich 2002; Karcz and Burdach 2002, 2007; Burdach et al. 2014). It is currently well established that auxin-induced growth in maize coleoptile segments involves $\mathrm{K}^{+}$uptake through voltage-dependent, inwardly rectifying $\mathrm{K}^{+}$channels (Zea mays $\mathrm{K}^{+}$channel 1 , ZMK1) and that apart from posttranslational, auxin-dependent up-regulation of the $\mathrm{K}^{+}$uptake channels, auxin also regulates the expression of the maize $\mathrm{K}^{+}$uptake gene ZMK1 (Philippar et al. 1999). Auxin also plays a primary role in the gravitropic response of monocot coleoptiles. Gravistimulation of maize seedlings (displacement of seedlings into a horizontal position) causes redistribution of IAA synthesized at coleoptile tip towards the lower coleoptile half. Due to increased auxin concentration, cells on the lower side of maize seedlings show growth enhanced in comparison to cells of the upper side, what results in upward bending of coleoptiles, against the force of gravity (negative gravitropic response) (Philippar et al. 1999). Interestingly, Philippar et al. (1999) have also shown that the differential expression of $Z M K 1$ between the upper and lower halves of gravistimulated coleoptiles is in line with the spatial and temporal pattern of auxin redistribution.

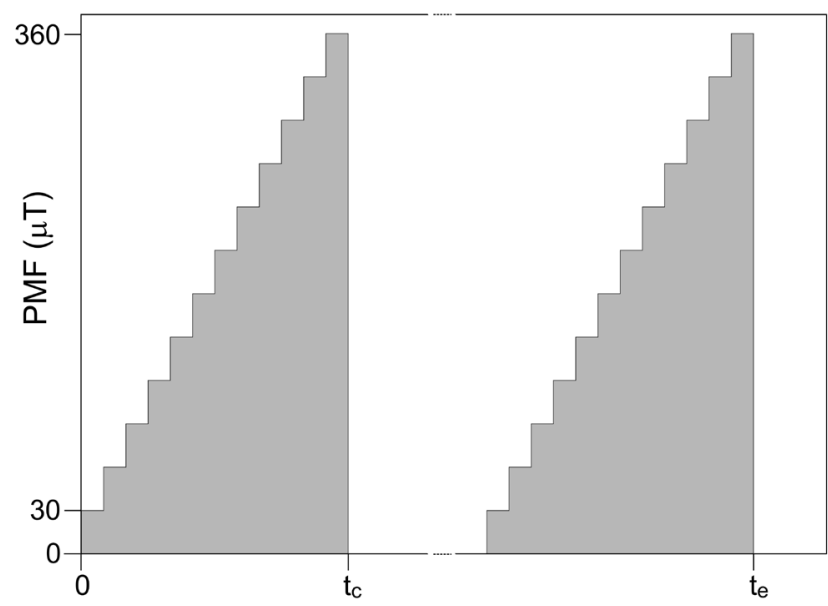

Figure 1. Stimulus protocol used for treatment of maize coleoptile cells with pulsed magnetic field (PMF). $t_{c}$, one cycle duration; $t_{e}$, duration of treatment with PMF (96 h). For detail see Materials and Methods.
The main objective of the present study was to determine the effect of pulsed magnetic field (PMF) on plant growth. This objective was realized by: (1) studying the effects of PMF on the length of maize seedling organs (root, mesocotyl and coleoptile); (2) determining the effect of PMF on the gravitropic response of maize seedlings; (3) studying the effects of PMF on both growth of coleoptile segments incubated with or without IAA and simultaneously with growth measured medium $\mathrm{pH}$. It should be added that segments excised from coleoptiles of grasses represent a classical model system for studies on the elongation growth of plant cells. In this system the number of cells is constant and organ grows by elongation only. Moreover, most of crucial evidence on the mechanisms of auxin action was obtained from maize coleoptile segments (Hager 2003). To the best of our knowledge, no research has been reported on the effect of pulsed magnetic field on gravitropic response and cell elongation in coleoptiles of maize seedlings.

\section{Materials and Methods}

\section{Plant material and magnetic treatment}

Caryopsis of maize (Zea mays L. cv. KOKA) were soaked in tap water for $2 \mathrm{~h}$, sown on wet lignin in plastic boxes $(19 \times 24 \mathrm{~m})$, and placed in a magnetic applicator, which in turn was kept in a growth chamber (Type MIR-533, Sanyo Electric Co., Japan) at $27 \pm 1^{\circ} \mathrm{C}$. Control caryopsis were kept under the same experimental conditions but in the absence of pulsed magnetic field (but with geomagnetic field of 50-54 $\mu \mathrm{T})$. The experiments were performed with $96 \mathrm{~h}$ old etiolated seedlings $(25-30 \mathrm{~mm})$ and $10-\mathrm{mm}$-long coleoptile segments excised from them. Coleoptile segments, with the first leaves removed, were excised $3 \mathrm{~mm}$ below the tip and collected in an intensively aerated medium of the following composition: $1 \mathrm{mM} \mathrm{KCl}, 0.1 \mathrm{mM} \mathrm{NaCl}, 0.1 \mathrm{mM} \mathrm{CaCl}_{2}$, initial pH 5.7-6.0, as previously described by Karcz and Burdach (2002) and Burdach et al. (2014).

PMF exposure was performed using the Viofor JPS device (Med \& Life, Komorow, Poland; www.medandlife. $\mathrm{com})$, including a ring-shaped applicator $(30 \mathrm{~cm}$ in diameter and $20 \mathrm{~cm}$ high) and control panel. Electromagnetic waves were generated as complex sequences of pulses with a frequency of basic impulse of 180-195 Hz. The PMF was generated using application mode $\mathrm{M} 2$, in which intensity of magnetic field increases from 30 to $360 \mu \mathrm{T}$ (in $30 \mu \mathrm{T}$ steps) for $12 \mathrm{~s}$ (Fig. 1). PMF was applied over a period of 96 hours, covering both germination of seeds and growth of seedlings. It should be added that the homogeneity of the PMF (estimated with the accuracy of 5\%) in the geometric centre of the applicator was kept in about $70 \%$ of its volume. The magnetic lines of force of PMF generated 
in the applicator were perpendicular to the long axis of the germinated seedlings, whereas ones for geomagnetic field were parallel. The geomagnetic field in the laboratory, where the experiments were performed, was in the range of 41-49 $\mu \mathrm{T}$ (50-54 $\mu \mathrm{T}$ in applicator off). This indicates that the PMF used in our experiments is a resultant force of both PMF and geomagnetic field. Our control experiments sense probably geomagnetic field only.

\section{Gravitropic response}

The curvature angle from the initial horizontal position of coleoptiles was recorded in 30 min intervals for $6 \mathrm{~h}$. Coleoptile bending was measured by means of the shadowgraph method at 18-fold magnification (Fig. 2). To generate "shadow" the halogen lamp $(50 \mathrm{~W})$ with green filter was used (light at about $510 \mathrm{~nm}$ with intensity of $0.25 \mathrm{~W} / \mathrm{m}^{2}$ ). During gravitropic response, maize seedlings were incubated in an intensively aerated medium of the same composition as described above. Temperature of incubation medium in the gravitropic response-measuring system was thermostatically controlled at a level of $25 \pm 0.5^{\circ} \mathrm{C}$. All manipulations and growth measurements were carried out under dim green light $\left(0.04 \mathrm{~W} / \mathrm{m}^{2}\right)$, which impinges omnilaterally on the coleoptiles.

\section{Growth and $\mathrm{pH}$ measurements}

Growth experiments were carried out with 4-day-old maize seedlings and $10-\mathrm{mm}$-long coleoptile segments excised from them. In seedlings, the length of roots, mesocotyls and coleoptiles was measured with a ruler to the nearest $1 \mathrm{~mm}$. Coleoptile segments were placed in apparatus for simultaneous measurements of segment elongation and $\mathrm{pH}$ of the incubation medium, as previously described (Karcz et al. 1990; Karcz and Burdach 2002). Optical system used in this apparatus for growth measurements by shadow-graph method permitted recording of the longitudinal extension of a stack of 21 segments. Volume of the incubation medium in the elongation and $\mathrm{pH}$-measuring system amounted to $6.3 \mathrm{ml}(0.3$ $\mathrm{ml} /$ segment). Coleoptile segments were incubated in an intensively aerated medium. The incubation medium also flowed through the lumen of coleoptile cylinders. This feature permitted experimental solution to be in direct contact with the interior of segments, what significantly enhanced both elongation growth of coleoptile segments and proton extrusion (Karcz et al. 1995). Medium circulation was driven by a peristaltic pump (1B-05A; Zalimp, Poland). Measurements of $\mathrm{pH}$ were performed with a $\mathrm{pH}$ electrode (OSH 10-10; Metron, Poland). Temperature of all solutions in the elongation and $\mathrm{pH}$-measuring system was thermostatically controlled at a level of $25 \pm 0.5^{\circ} \mathrm{C}$.

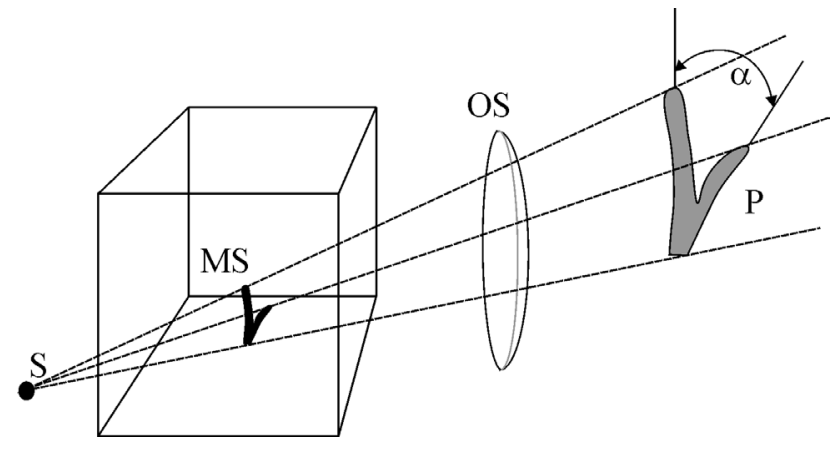

Figure 2. Front view of the apparatus used for measurements of coleoptile bending in response to a $90^{\circ}$ gravistimulation of maize seedlings. The coleoptile bending was measured by means of a shadow-graph method at $18 \times$ magnification. During gravitropic responses maize seedlings were incubated in an intensively aerated medium of the following composition: $1 \mathrm{mM} \mathrm{KCl}, 0.1 \mathrm{mM}, \mathrm{NaCl}$ 0.1, $\mathrm{mM} \mathrm{CaCl}_{2}$, initial pH 5.7-6.0. MS, maize seedling; OS, optical system; $\mathrm{S}$, source of light; $\mathrm{P}$, picture of the coleoptile bending; $\alpha$, angle of bending.

All manipulations and growth measurements were carried out under dim green light.

\section{Statistical analysis}

Data were analysed with Statistica software for Windows (version 8.0). Differences between individual treatments and the control were analysed using one-way ANOVA and the least significant difference (LSD) test. Statistical significance was defined at $p<0.05$.

\section{Results}

Data in Figure 3 indicate that in seedlings treated with the PMF only coleoptile growth was inhibited by about $16 \%$ as compared to the control, while growth of roots and mesocotyls did not depend on PMF (not significantly different from the control using LSD test at $p<0.05$ ). Taking into account the above, we subjected coleoptiles of maize seedlings to further experiments, carried out in two variants. In the first one, gravitropic reaction was measured in seedlings grown in the presence of PMF, while in the second PMF was applied only during gravistimulation. Figure 4, showing the effect of $\mathrm{PMF}$ on the gravitropic response of seedlings, indicates that the response was inhibited by $36 \%$ in seedlings grown in the presence of PMF. However, when magnetic field was applied during gravistimulation (within $6 \mathrm{~h}$ ), only slight inhibition (of about $8 \%$ at $6 \mathrm{~h}$, statistically significant at $p<0.05$, LSD test) was observed. As mentioned in the Introduction, coleoptile segments excised from maize seedlings serve as a clas- 


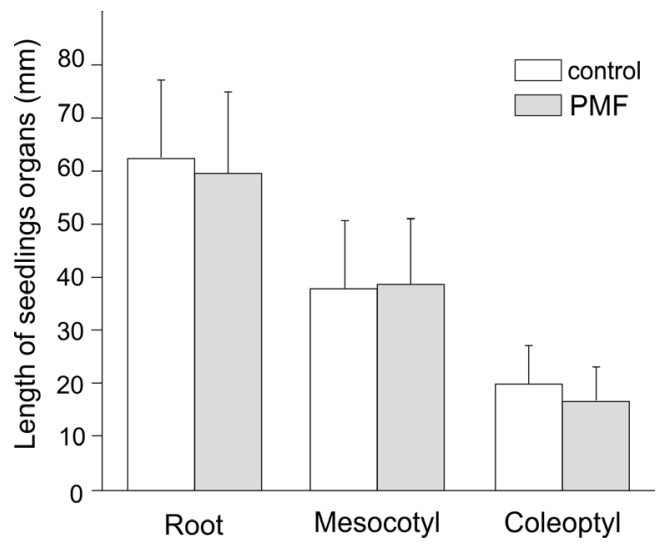

Figure 3. Effect of pulsed magnetic field (PMF) on the length $(\mathrm{mm})$ of organs in maize (Zea mays L.) seedlings. Length of roots, mesocotyls and coleoptiles of 100 seedlings was measured with a ruler to the nearest $1 \mathrm{~mm}$. Values are means $\pm \mathrm{SD}(n=10)$. Only length of the coleoptiles treated with PMF differ significantly as compared to the control (LSD test $p<0.05$ ).

sical model system for studies on the elongation growth of plant cells. Considering the above mentioned, we performed other experiments with coleoptile segments, investigating the effect of PMF on endogenous growth (growth in control medium), growth in the presence of IAA and on medium $\mathrm{pH}$ changes measured simultaneously with growth. The used coleoptile segments were excised from seedlings grown in the presence of PMF. Data in Figure 5 evidence that endogenous growth of maize coleoptile segments excised from seedlings treated with the PMF was stimulated by $52 \%$ as compared to control $(834.6 \pm 196.9 \mu \mathrm{m} / \mathrm{cm}$, mean $\pm \mathrm{SD}, n=10)$. As can be seen in Figure 5, addition (after $2 \mathrm{~h}$ of segment preincubation) of auxin to the medium containing coleoptile segments untreated with the PMF induced their strong elongation growth, about two-fold greater than in the control (auxinfree medium). However, when IAA was added (after $2 \mathrm{~h}$ of segment preincubation) to the medium containing coleoptile segments excised from PMF-treated seedlings, stimulation of elongation growth was about $30 \%$ greater as compared to growth of segments incubated in the presence of IAA only. Results collected in Figure 5 (inset) also provided basis for the analysis of growth rate kinetics. Auxin appeared to induce strong growth, kinetics of which can be divided into two phases (biphasic reaction). The first phase, very rapid, was followed by a long-lasting one, which began about $30 \mathrm{~min}$ after auxin addition. In coleoptile segments treated with the PMF, amplitude of the first phase of IAA-induced growth rate was significantly higher than that induced by IAA in PMF untreated coleoptile segments. Data obtained for medium $\mathrm{pH}$, measured simultaneously with growth (Fig. 6), indicated that coleoptile segments incubated in the auxin-free medium changed its $\mathrm{pH}$ in a specific manner. Generally, within the first 2-3 $\mathrm{h}$ an increase of $\mathrm{pH}$ was observed, followed by a slow decrease to $\mathrm{pH}$ of approximately 5.4-5.5, after $7 \mathrm{~h}$. Addition of IAA (after $2 \mathrm{~h}$ of segment preincubation) to the auxin-free medium caused a stronger decrease in $\mathrm{pH}$, to 5.0. In order to present $\mathrm{pH}$ changes in the medium much more suggestively, they have been shown as changes of $\mathrm{H}^{+}$concentration per coleoptile segment $\left(\left[\mathrm{H}^{+}\right] / \mathrm{cm}\right)$ (Fig. 6 , inset). As indicated in Figure 6 (inset), IAA-induced proton extrusion, expressed as difference between $\mathrm{H}^{+}$concentration at 7 and $2 \mathrm{~h}\left(\Delta\left[\mathrm{H}^{+}\right]\right)$, was 5.5 -fold greater than in the control medium (auxin-free medium). The characteristic pattern of $\mathrm{pH}$ changes observed in external medium without auxin was only partly disturbed in coleoptile segments excised from seedlings treated with the PMF (Fig. 6). In turn, when IAA was added to a medium containing coleoptile segments treated with the PMF, the rate of acidification was lower than in untreated segments (Fig. 6). In this last case, the addition of IAA to a medium containing PMF-treated coleoptile segments produced 2.5-fold lower proton extrusion (expressed as $\Delta\left[\mathrm{H}^{+}\right] / \mathrm{cm}$ ) than in untreated segments ( $2.5 \mathrm{nmol} / \mathrm{segment})$ (Fig. 6, inset).

\section{Discussion}

The main aim of the present study was to establish a link between signal transduction pathways in response to auxin (IAA) and abiotic factors such as magnetic field. It should be emphasized that in spite of abundant literature on the mechanism by which auxin controls growth of grass coleoptiles, little is known about its action in the presence of magnetic field other than the geomagnetic field. To the best

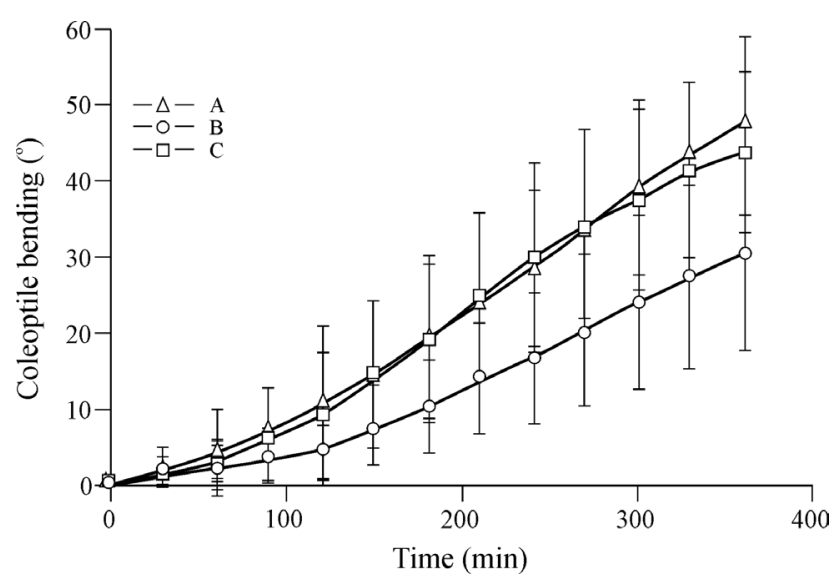

Figure 4. Bending of maize coleoptiles (measured in $30 \mathrm{~min}$ intervals for $6 \mathrm{~h} ; 0-360 \mathrm{~min}$ ) in response to $90^{\circ}$ gravistimulation. A. Bending of coleoptiles untreated with the PMF. B. Bending of coleoptiles grown in the presence of PMF. C. Bending of coleoptiles treated with the MF during gravistimulation (within $6 \mathrm{~h}$ ). Values are means $\pm \mathrm{SD}(n=10)$. 


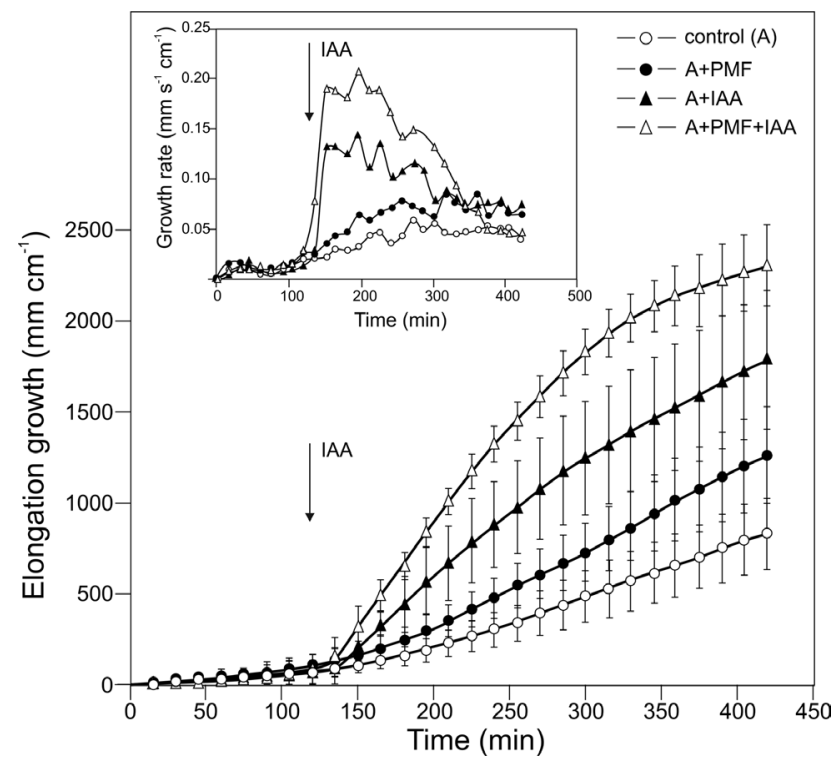

Figure 5. Effect of pulsed magnetic field (PMF) on the elongation growth of maize coleoptile segments incubated in the presence or absence of $10 \mu \mathrm{M}$ indole-3-acetic acid (IAA). The elongation growth of a stack of 21 segments was measured as described in Materials and Methods. IAA was added to the incubation medium at $2 \mathrm{~h}$. Inset shows the growth rate of maize coleoptile segments. All curves represent means of ten independent experiments. Bars indicate \pm SD.

of our knowledge, the effect of magnetic field on gravitropic response and cell elongation in coleoptiles of maize seedlings has not been previously examined. As can be seen in Figure 3, maize seedlings grown in the presence of pulsed magnetic field had significantly shorter coleoptiles than control seedlings (untreated with PMF). Numerous studies have shown that in maize auxin is biosynthesized at coleoptile tip, from which it is transported basipetally to lower tissues (Mori et al. 2005; Nishimura et al. 2006, 2011; Matsuda et al. 2011). Constant supply of auxin from the coleoptile tip is required for growth stimulation of cells in the elongation region of coleoptiles (Iino 1982; Mori et al. 2005; Matsuda et al. 2011). Regulation of IAA biosynthesis and/or transport is controlled by environmental stimuli (Iino 1982; Fuchs et al. 2003; Mori et al. 2005; Nishimura et al. 2006; Matsuda et al. 2011). Only recently it has been shown that magnetic field causes accumulation of auxin in the root tip of Arabidopsis seedlings (Manzano et al. 2013; Herranz et al. 2014). The authors also suggested that inhibition of polar auxin transport by the magnetic field produces the same pattern of auxin distribution as after drug-induced transport inhibition with naphthylphtalamic acid (NPA). It should be pointed out that application of NPA, an IAA transport inhibitor (auxin efflux inhibitor; Sussman and Goldsmith 1981), at the very tip region of the coleoptiles nearly completely prevented
IAA movement from the tip and severely suppressed their gravitropic bending (Mori et al. 2005; Nishimura et al. 2009, 2011). From the above observations, it could be concluded that inhibition of coleoptile elongation in seedlings grown in the presence of PMF is caused by blockage of polar auxin transport. This suggestion is also supported by results obtained in our experiments with gravistimulated maize seedlings. Our data show clearly that PMF, independently on the variant of experiment, suppresses gravitropic response of coleoptiles (Fig. 4), probably due to lower differential downward stream of auxin synthesized at coleoptile tip, resulting from PMF-driven blocking of polar auxin transport. At present, there is no doubt, at least for maize, that the differential downward stream of auxin synthesized at the tip of coleoptiles plays a key role in their gravitropic response (Iino 1995; Philippar et al. 1999; Mori et al. 2005; Nishimura, et al. 2009, 2011; Matsuda et al. 2011). Suppression of gravitropic response was also observed in flax (Linum bienne L.) apical shoot segments, with leaves removed, by Belova and Lednev (2001), at magnetic field with a flux density of $100 \mu \mathrm{T}$. The authors proposed that this inhibition might be initiated by the effect of magnetic field on $\mathrm{Ca}^{2+}$-dependent reactions. Data in Figure 5 indicate that endogenous growth of maize coleoptile segments excised from seedlings treated with PMF

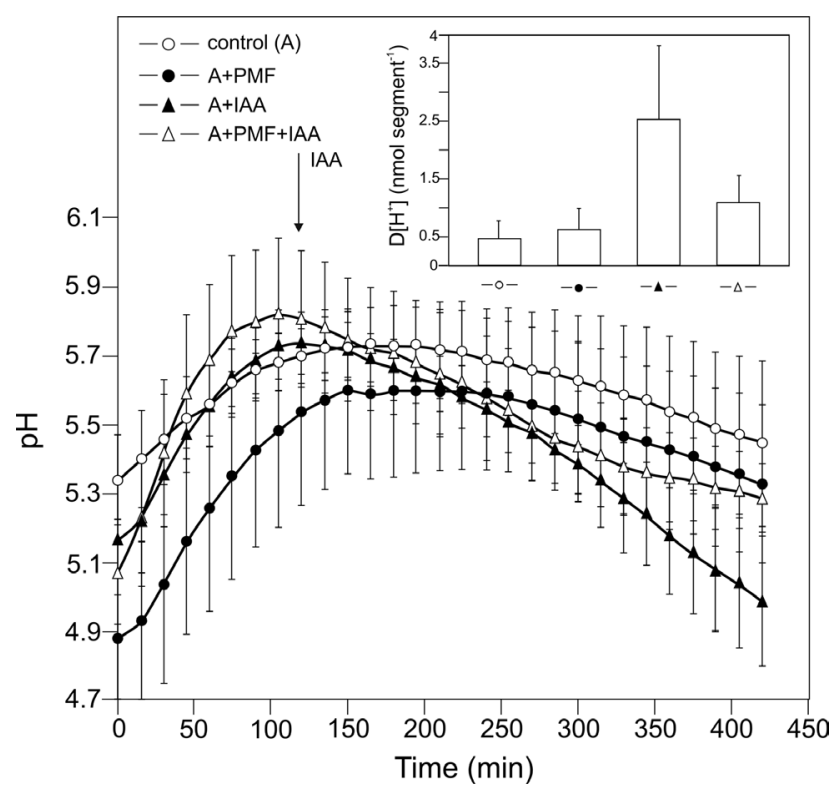

Figure 6. Effect of pulsed magnetic field (PMF) on the medium $\mathrm{pH}$ of maize coleoptile segments incubated in the presence or absence of $10 \mu \mathrm{M}$ indole-3-acetic acid (IAA). Values for $\mathrm{pH}$ are means of ten independent experiments performed simultaneously with growth (Fig. 4). Inset shows medium $\mathrm{pH}$ expressed as $\Delta\left[\mathrm{H}^{+}\right]$, where $\Delta\left[\mathrm{H}^{+}\right]$ means difference between $\mathrm{H}^{+}$concentration $\left(\left[\mathrm{H}^{+}\right]\right)$at $420 \mathrm{~min}$ and $120 \mathrm{~min}$. Columns represent means that are significantly different according to LSD test $(p<0.05)$. 
is higher by $52 \%$ as compared to control (segments untreated with the PMF). It was previously speculated that endogenous growth of auxin-depleted coleoptile segments (the so called "spontaneous growth response") was caused by stimulation of IAA synthesis in coleoptile segments (Evans and Schmitt 1975; Weiler et al. 1981) or by a change in tissue sensitivity to low concentrations of endogenous auxin, remaining after segment excision (Vesper and Evans 1978). Thus, it is possible that in segments excised from maize seedlings PMF increased either their sensitivity to endogenous IAA or the IAA synthesis. These two phenomena may account for the stimulatory effect of PMF on the endogenous growth of coleoptile segments. Another possibility is that by inhibiting polar auxin transport, resulting in the same pattern of auxin distribution as observed in the presence of NPA, PMF may enhance accumulation of IAA in coleoptile cells, causing concomitant increase in growth. There is evidence in literature that after blocking the efflux of IAA from cells with NPA, the growth of maize coleoptile segments was sustained, even when extracellular auxin was removed from the incubation medium (Vesper and Kuss 1990). Results obtained for medium $\mathrm{pH}$, measured simultaneously with growth, indicated that coleoptile segments treated with the PMF are much more effective in proton extrusion than control segments. This observation is in line with the so called "acid growth theory" of auxin action. Data presented in Figure 5 and 6, showing that IAA accelerates elongation growth and enhances proton extrusion in coleoptile segments, as compared to control medium (IAA-free medium), are in good agreement with findings of various authors (Kutschera and Schopfer 1985; Karcz et al. 1990; Lüthen et al. 1990; Karcz and Burdach 2002; Hager 2003; Kurtyka et al. 2011; Burdach et al. 2014). Similarly to endogenous growth (growth induced by endogenous auxin), IAA-induced growth of PMF-treated coleoptile segments was greater than in untreated seedlings (by $30 \%$ ). In IAA-free medium, PMF-treated segments extruded much more protons than untreated segments. However, when treated with PMF and subsequently incubated in the presence of IAA, coleoptile segments extruded 2.5-fold less protons as compared to segments treated with IAA only. This may indicate that PMF, at least partly, inhibits IAA-induced plasma membrane $\mathrm{H}^{+}$-ATPase activity. Although this observation seems to contradict the "acid growth theory" of auxin action, the question about the extent to which endogenous and IAA-induced growth depend on cell wall acidification remains open. Inhibition of IAA-induced plasma membrane $\mathrm{H}^{+}$-ATPase activity by the PMF is likely to result from PMF-induced increase in cytosolic $\mathrm{Ca}^{2+}$ concentration (Belyavskaya 2001; Pazur and Rassadina 2009), since increase in $\left[\mathrm{Ca}^{2+}\right]_{\text {cyt }}$ impairs plasma membrane $\mathrm{H}^{+}$-ATPase activity (Kinoshita et al. 1995; Brault et al. 2004). Another possibility is that either in the presence or absence of IAA magnetic field enhances elongation growth of plant cells by inducing uptake of osmotically active ions, particularly $\mathrm{K}^{+}$. This suggestion is supported by experiments in which the magnetic field increased accumulation of various macroelements, including potassium (Belyavskaya 2001; Stange et al. 2002; Dhawi et al. 2009; Radhakrishnan and Kumari 2012).

To conclude, results presented in this paper demonstrate that the mechanism by which pulsed magnetic field alters the gravitropic response and cell elongation in coleoptiles of maize seedlings involves regulation of both auxin transport proteins and plasma membrane $\mathrm{H}^{+}$-ATPase activity.

\section{References}

Becker D., Hedrich R. (2002): Channelling auxin action: modulation of ion transport by indole-3-acetic acid. Plant Mol. Biol. 49, 349-356 http://dx.doi.org/10.1023/A:1015211231864

Belova N. A., Lednev V. V. (2001): Activation and inhibition of gravitropic response in the segments of flax stems exposed to the static magnetic field with magnetic flux density ranging from 0 to $350 \mu$ T. Biofizika 46, 118-121 (in Russian)

Belyavskaya N. A. (2001): Ultrastructure and calcium balance in meristem cells of pea roots exposed to extremely low magnetic fields. Adv. Space Res. 28, 645-650 http://dx.doi.org/10.1016/S0273-1177(01)00373-8

Belyavskaya N. A. (2004): Biological effects due to weak magnetic field on plants. Adv. Space Res. 34, 1566-1574 http://dx.doi.org/10.1016/j.asr.2004.01.021

Brault M., Amiar Z., Pennarun A. M., Monestiez M., Zhang Z., Cornel D., Dellis O., Knight H., Bouteau F., Rona J. P. (2004): Plasma membrane depolarization induced by abscisic acid in Arabidopsis suspension cells involves reduction of proton pumping in addition to anion channel activation, which are both Ca2+ dependent. Plant Physiol. 135, 231-243 http://dx.doi.org/10.1104/pp.104.039255

Burdach Z., Kurtyka R., Siemieniuk A., Karcz W. (2014): Role of chloride ions in the promotion of auxin-induced growth of maize coleoptile segments. Ann. Bot. 114, 1023-1034 http://dx.doi.org/10.1093/aob/mcu170

Cleland R. E., Prins H. B. A., Harper J. R., Higinbotham N. (1977): Rapid hormone-induced hyperpolarization of the oat coleoptile transmembrane potential. Plant Physiol. 59, 395-397 http://dx.doi.org/10.1104/pp.59.3.395

Dhawi F., Al-Khayri J. M., Essam H. (2009): Static magnetic field influence on elements composition in date palm (Phoenix dactylifera L.). Res. J. Agric. Biol. Sci. 5, 161-166

Dhawi F. (2014): Why magnetic fields are used to enhance a plant's growth and productivity? Ann. Res. Rev. Biol. 4, 886-896 http://dx.doi.org/10.9734/ARRB/2014/5983

Evans M. L., Schmitt M. R. (1975): The nature of spontaneous changes in growth rate in isolated coleoptile segments. Plant Physiol. 55, 757-762 http://dx.doi.org/10.1104/pp.55.4.757

Fuchs I., Philippar K., Ljung K., Sandberg G., Hedrich, R. (2003): Blue light regulates an auxin-induced $\mathrm{K}+$-channel gene 
in the maize coleoptile. Proc. Natl. Acad. Sci. USA 100, $11795-11800$

http://dx.doi.org/10.1073/pnas.2032704100

Galland P., Pazur A. (2005): Magnetoreception in plants. J. Plant

Res. 118, 371-389 http://dx.doi.org/10.1007/s10265-005-0246-y

Hager A., Menzel H., Krauss A. (1971): Experiments and hypothesis concerning the primary action of auxin in elongation growth. Planta 100, 47-75 (in German) http://dx.doi.org/10.1007/BF00386886

Hager A., Debus G., Edel H. G., Stransky H., Serrano R. (1991) Auxin induces exocytosis and therapid synthesis of a high turnover pool of plasma membrane H+-ATPase. Planta 185, $527-537$ http://dx.doi.org/10.1007/BF00202963

Hager A. (2003): Role of the plasma membrane H+-ATPase in auxin induced elongation growth: historical and new aspects. J. Plant Res. 116, 483-505 http://dx.doi.org/10.1007/s10265-003-0110-x

Herranz R., Valbuena M. A., Youssef K., Medina F-J. (2014): Mechanisms of disruption of meristemstic competence by microgravity in Arabidopsis seedlings. Plant Signal. Behav. 9, 1-6 http://dx.doi.org/10.4161/psb.28289

Iino M. (1982): Action of red light on indole-3-acetic-acid status and growth in coleoptiles of etiolated maize seedlings. Planta 156, 21-32 http://dx.doi.org/10.1007/BF00393439

Iino M. (1995): Gravitropism and phototropism of maize coleoptiles: evaluation of the Cholodny-Went theory through effects of auxin application and decapitation. Plant Cell Physiol. 36, 361-367

Karcz W., Stolarek J., Pietruszka M., Małkowski E. (1990): The dose-response curves for IAA induced elongation growth and acidification of the incubation medium of Zea mays coleoptile segments. Physiol. Plant. 80, 257-261

http://dx.doi.org/10.1111/j.1399-3054.1990.tb04405.x

Karcz W., Stolarek J., Lekacz H., Kurtyka R., Burdach Z. (1995): Comparative investigation of auxin and fusicoccin-induced growth and $\mathrm{H}+$-extrusion in coleoptile of Zea mays L. Acta Physiol. Plant. 17, 3-8

Karcz W., Burdach Z. (2002): A comparison of the effects of IAA and 4-Cl-IAA on growth, proton secretion and membrane potential in maize coleoptile segments. J. Exp. Bot. 53, 1089-1098 http://dx.doi.org/10.1093/jexbot/53.371.1089

Karcz W., Burdach Z. (2007): Effect of temperature on growth, proton extrusion and membrane potential in maize (Zea mays L.) coleoptile segments. Plant Growth Regul. 52, 141-150 http://dx.doi.org/10.1007/s10725-007-9184-0

Keller C. P., Van Volkenburgh E. (1996): Osmoregulation by oat coleoptile protoplasts (effect of auxin). Plant Physiol. 110, 1007-1016

Kinoshita T., Nishimura M., Shimazaki K. I. (1995): Cytosolic concentration of $\mathrm{Ca} 2+$ regulates the plasma membrane $\mathrm{H}+$-ATPase in guard cells of fava bean. Plant Cell 7, 1333-1342 http://dx.doi.org/10.1105/tpc.7.8.1333

Kurtyka R., Kita A., Karcz W. (2011): Fusicoccin counteracts the toxic effect of cadmium on the growth of maize coleoptile segments. Arch. Environ. Contam. Toxicol. 61, 568-577 http://dx.doi.org/10.1007/s00244-011-9662-2
Kutschera U., Schopfer P. (1985): Evidence against the acid-growth theory of auxin action. Planta 163, 483-493 http://dx.doi.org/10.1007/BF00392705

Lüthen H., Bigdon M., Böttger M. (1990): Re-examination of the acid-growth theory of auxin action. Plant Physiol. 93, 931-939 http://dx.doi.org/10.1104/pp.93.3.931

Maffei M. E. (2014): Magnetic field effects on plant growth, development, and evolution. Front. Plant Sci. 5, 1-14 http://dx.doi.org/10.3389/fpls.2014.00445

Manzano A. S., Larkin O. J., Dijkstra C. E., Anthony P., Davery M. R., Eaves L., Hill, R. J A., Herranz R., Medina F. J. (2013): Meristematic cell proliferation and ribosome biogenesis are decoupled in diamagnetically levitated Arabidopsis seedlings. BMC Plant Biol. 13, 214-129 http://dx.doi.org/10.1186/1471-2229-13-124

Matsuda S., Kajizuka T., Kadota A., Nishimura T., Kosiba T. (2011): NPH3- and PGP-like genes are exclusively in the apical tip region essential for blue-light perception and lateral auxin transport in maize coleoptiles. J. Exp. Bot. 62, 3459-3466

http://dx.doi.org/10.1093/jxb/err019

Minorsky P. V. (2007): Do geomagnetic variations affect plant function? J. Atmosph. Solar-Terres. Phys. 69, 1770-1774

Mori Y., NishimuraT., Kosiba T. (2005): Vigorous synthesis of indole-3-acetic acid in the apical very tip leads to a constant basipetal flow of the hormone in maize coleoptiles. Plant Sci. 168, 467-473

http://dx.doi.org/10.1016/j.plantsci.2004.09.010

Nishimura T., Mori Y., Furukawa T., Kadota A., Kosiba T. (2006): Red light causes a reduction in IAA levels at the apical tip by inhibiting de novo biosynthesis in maize coleoptiles. Planta 224, 1427-1435 http://dx.doi.org/10.1007/s00425-006-0311-3

Nishimura T., Nakano H., Hayashi K., Niwa C., Koshiba T. (2009): Differential downward stream of auxin synthesized at the tip has a key role in gravitropic curvature via TIR/AFBs-mediated auxin signaling pathways. Plant Cell Physiol. 50, 1874-1885 http://dx.doi.org/10.1093/pcp/pcp129

Nishimura T., Toyooka K., Sato M., Matsumoto S., Lucas M. M, Strnad M., Baluska F., Kosiba T. (2011): Immunohistochemical observation of indole-3-acetic acid at the IAA synthetic maize coleoptile tips. Plant Signal. Behav. 6, 2013-2022 http://dx.doi.org/10.4161/psb.6.12.18080

Occhipinti A., De Santis A., Maffei M. E. (2014): Magnetoreception: unavoidable step for plant evolution? Trends Plant Sci. $19,1-4$ http://dx.doi.org/10.1016/j.tplants.2013.10.007

Pazur A., Rassadina V. (2009): Transient effect of weak electromagnetic fields on calcium ion concentration in Arabidopsis thaliana. BMC Plant Biol. 9, 1-9 http://dx.doi.org/10.1186/1471-2229-9-47

Philippar K., Fuchs I., Lüthen H., Hoth S., Bauer C. S., Haga K., Thiel G., Ljung K., Sandberg G., Böttger M., Becker D., Hedrich, R. (1999): Auxin-induced K+ channel expression represents an essential step in coleoptile growth and gravitropism. Proc. Natl. Acad. Sci. USA 96, 12186-12191 http://dx.doi.org/10.1073/pnas.96.21.12186 
Radhakrishnan R., Kumari B. D. R. (2012): Pulsed magnetic field: A contemporary approach offers to enhance plant growth and yield of soybean. Plant Physiol. Biochem. 51, 139-144 http://dx.doi.org/10.1016/j.plaphy.2011.10.017

Rayle D. L., Cleland D. L. (1970): Enhancement of wall loosening and elongation by acid solutions. Plant Physiol. 46, 250-253 http://dx.doi.org/10.1104/pp.46.2.250

Rayle D. L., Cleland D. L. (1992): The acid growth theory of auxininduced cell elongation is alive and well. Plant Physiol. 99, $1271-1274$ http://dx.doi.org/10.1104/pp.99.4.1271

Stange B. C., Rowland R. E., Rapley B. I., Podd J. V. (2002): ELF magnetic field increase amino acid uptake into Vicia faba $L$. roots and alter ion movement across the plasma membrane. Bioelectromag. 33, 347-354 http://dx.doi.org/10.1002/bem.10026

Sussman M. R., Goldsmith M. H. M. (1981): The action of specific inhibitors of auxin transport on uptake of auxin and binding of N-1-naphthylphthalamic acid to a membrane site in maize coleoptiles. Planta 152, 13-18 http://dx.doi.org/10.1007/BF00384978

Teixeira da Silva J. A., Dobránszki J. (2015): How do magnetic fields affect plants in vitro? In Vitro Cell. Dev. Biol. Plant. 51, 233-240 http://dx.doi.org/10.1007/s11627-015-9675-z

Teixeira da Silva J. A., Dobránszki J. (2016): Magnetic fields: haw is plant growth and development impacted? Protoplasma 253, 231-248 http://dx.doi.org/10.1007/s00709-015-0820-7

Vesper M. J., Evans M. L. (1978): Time-dependent changes in the auxin sensitivity of coleoptile segments. Plant Physiol. 61, 204-208 http://dx.doi.org/10.1104/pp.61.2.204

Vesper M. J., Kuss C. L. (1990): Physiological evidence that the primary site of auxin action is an intracellular site. Planta 182, 486-491 http://dx.doi.org/10.1007/BF02341022

Weiler E. W., Jourdan P. S., Conrad W. (1981): Levels of indole-3acetic acid in intact and decapitated coleoptiles as determined by a specific and highly sensitive solid-phase enzyme immuno assay. Planta 153, 561-571 http://dx.doi.org/10.1007/BF00385542

Received: December 14, 2015

Final version accepted: March 1, 2016

First published online: July 22, 2016 